\title{
Poéticas blandas: ondulantes, sinuosas y distorsiones
}

\section{Artículo de investigación artística}

\author{
John Castles \\ Creador invitado \\ johncastlesg@gmail.com \\ Universidad Distrital Francisco José de Caldas
}

$-$

Recibido: 10 de diciembre de 2017

Aprobado: 20 de diciembre de 2017

Cómo citar este artículo: Castles, John. (2018) Poéticas blandas: ondulantes, sinuosas y distorsiones (20062017). Calle14: revista de investigación en el campo del arte 13 (23) pp. 16-37. DOI: https://doi. org/10.14483/21450706.12986 
Poéticas blandas: ondulantes, sinuosas y distorsiones (2006-2017)

\begin{abstract}
Resumen
Este articulo ofrece una muestra significativa del trabajo plástico y visual realizado por John Castles en la última década. Las imágenes de las obras son acompañadas por breves pronunciamientos de especialistas, teóricos y curadores latinoamericanos. De esta manera, se puede ver la relación de complementariedad que se establece entre la sensibilidad y el pensamiento en la poesía-plástica que atraviesa la extensa obra del autor.
\end{abstract}

\title{
Palabras claves
}

Escultura, arte colombiano, arte no representacional, arte público.

Soft poetics: undulating, sinuous and distortions (2006-2017)

\begin{abstract} work of the author.

\section{Keywords}

Sculpture, Colombian art, non-representational art, public art.
\end{abstract}

This article offers a significant sample of the plastic and visual work done by John Castles in the last decade. The images of the works are accompanied by short statements by Latin American specialists, theorists and curators. Thus, we can see the relation of complementarity that is established between sensitivity and thought in the plastic-poetry that crosses the extensive

Poétiques douces : ondulées, sinueuses et distorsions (2006-2017)

\section{Résumé}

Cet article offre un échantillon significatif du travail plastique et visuel effectué par John Castles au cours de la dernière décennie. Les images des œuvres sont accompagnées de courtes déclarations de spécialistes, de théoriciens et de conservateurs latino-américains. Ainsi, nous pouvons voir la relation de complémentarité qui s'établit entre la sensibilité et la pensée dans la poésie-plastique qui traverse le vaste travail de l'artiste.

\section{Mots clés}

Sculpture, art colombien, art non figuratif, art public.

Poéticas suaves: ondulantes, sinuosas e distorçães (2006-2017)

\section{Resumo}

Este artigo oferece uma amostra significativa do trabalho plástico e visual feito por John Castles na última década. As imagens das obras são acompanhadas por breves declarações de especialistas, teóricos e curadores latino-americanos. Desta forma, podemos ver a relação de complementaridade que se estabelece entre a sensibilidade e o pensamento na poesia plástica que atravessa o extenso trabalho do autor.

\section{Palavras chaves}

Escultura, arte colombiana, arte não representacional, arte pública. 
Landu virsiai: Ridundu, wistu i sugrichakuna (2016- 2017)

Maillallachiska:

Kai kilkakuna tsabaju kawachimi landu i kawachirimi imasami kai wagki suti Jhon Castles ña wata puchukambapa ura, kai kawachii kami ruraska sug wagkikunawa, kilkakuna i ambidurkunawa kai alpa latinoamericakumandakuna. Chasami kai tsbaju tukuimi allilla puchukamkuna allí iuiaspai i kai kilkaikuna iapa suma llunchiskapi chasa kai ruralapa pin kilkaskamika.

Rimangapa Ministidukuna:

Ruraikuna, kai Culumbianomi i rurai aschai kawachirimi Tukui maikanmi munaska gintita. 


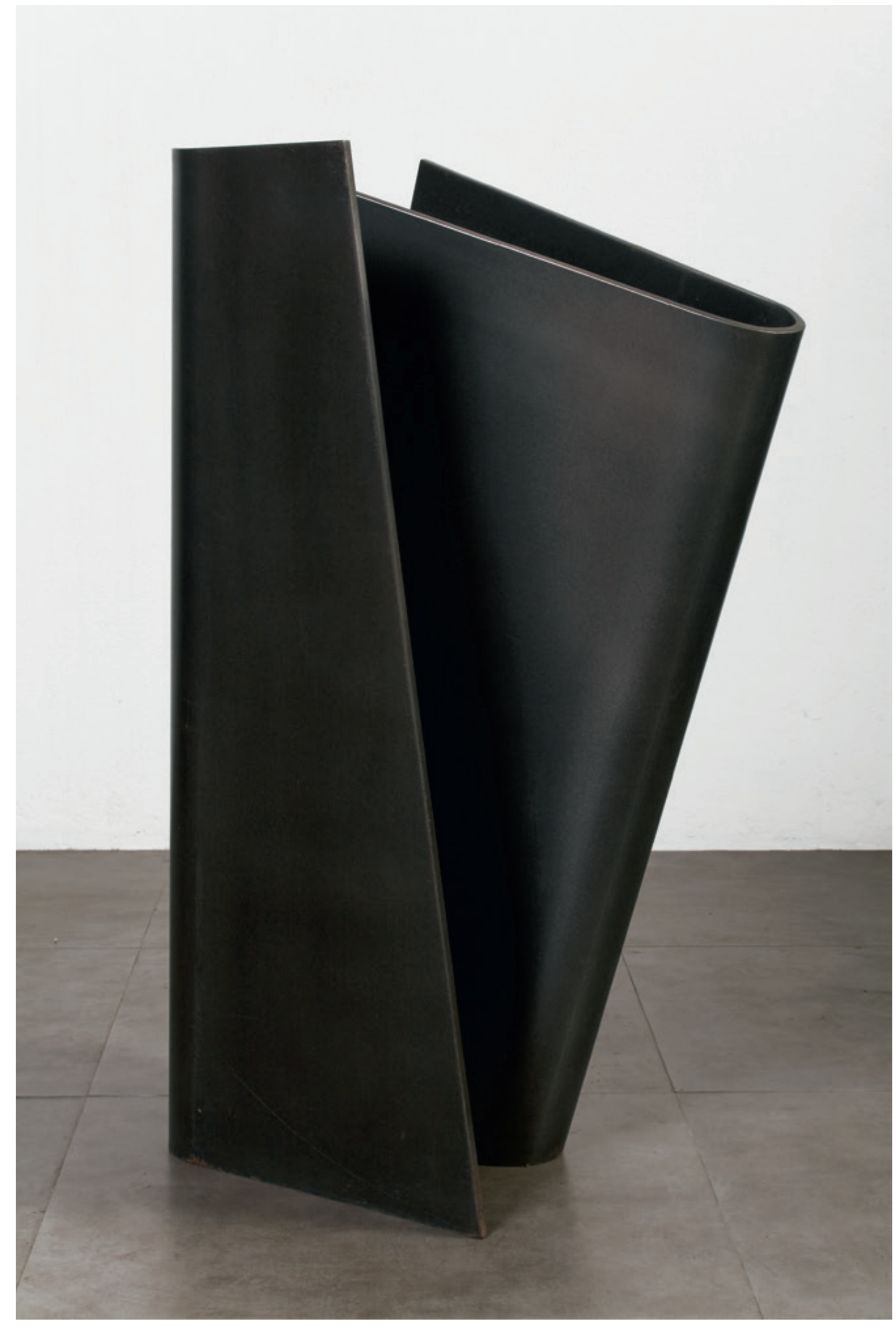




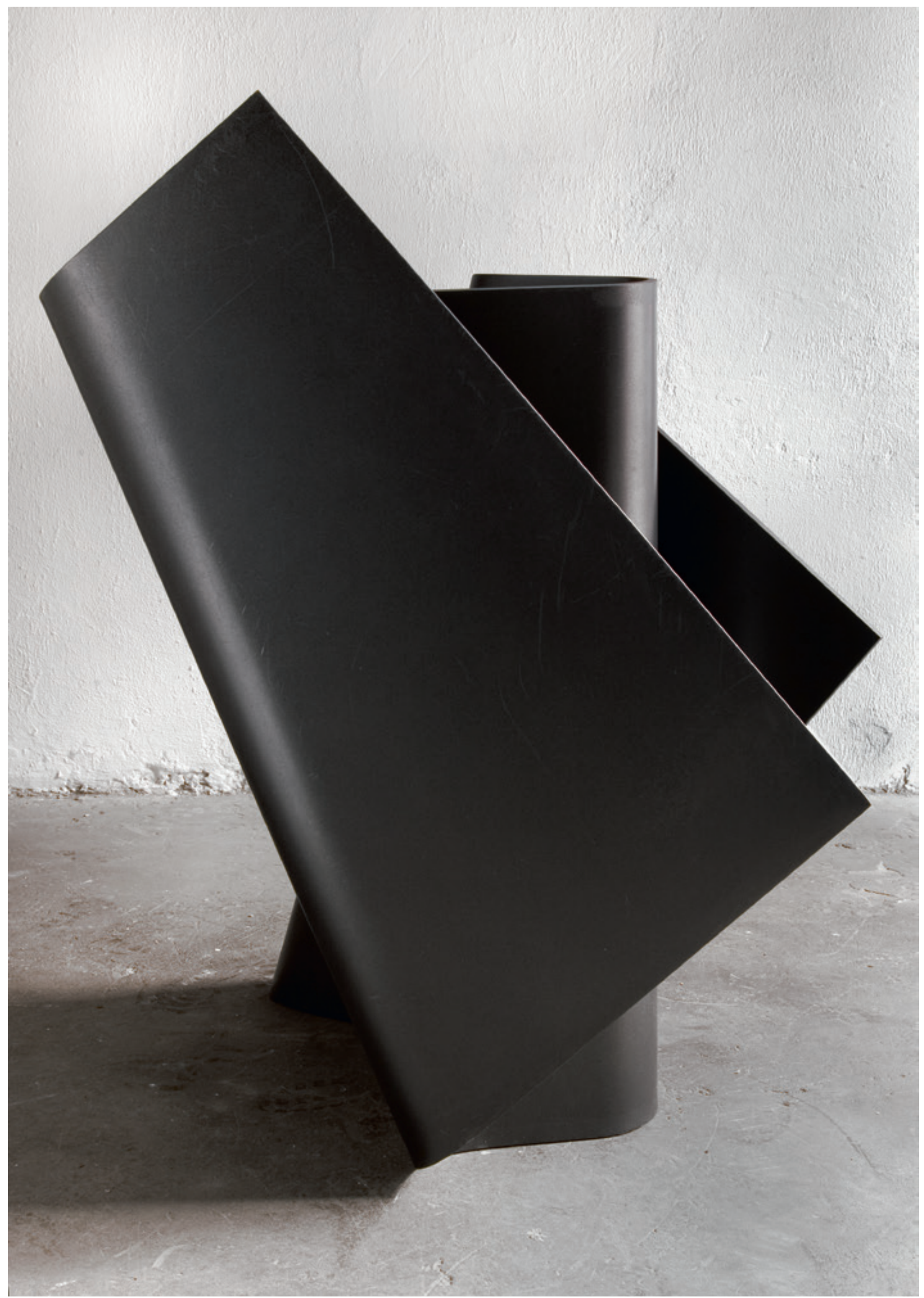




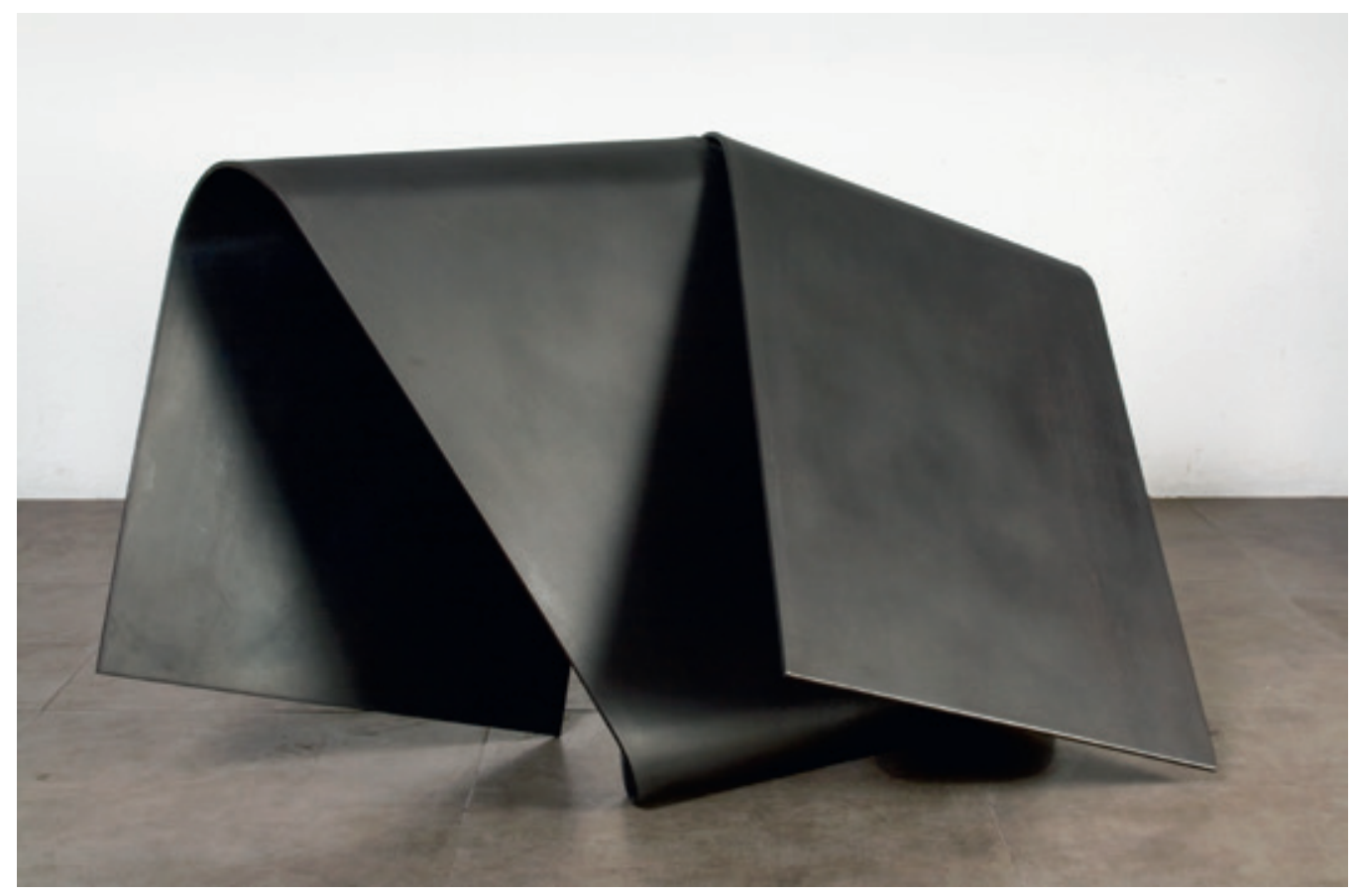

Envolvente horizontal 3, (John Castles 2008), acero, 85 x 125 × 56 cm. Fotografía: Ernesto Monsalve.

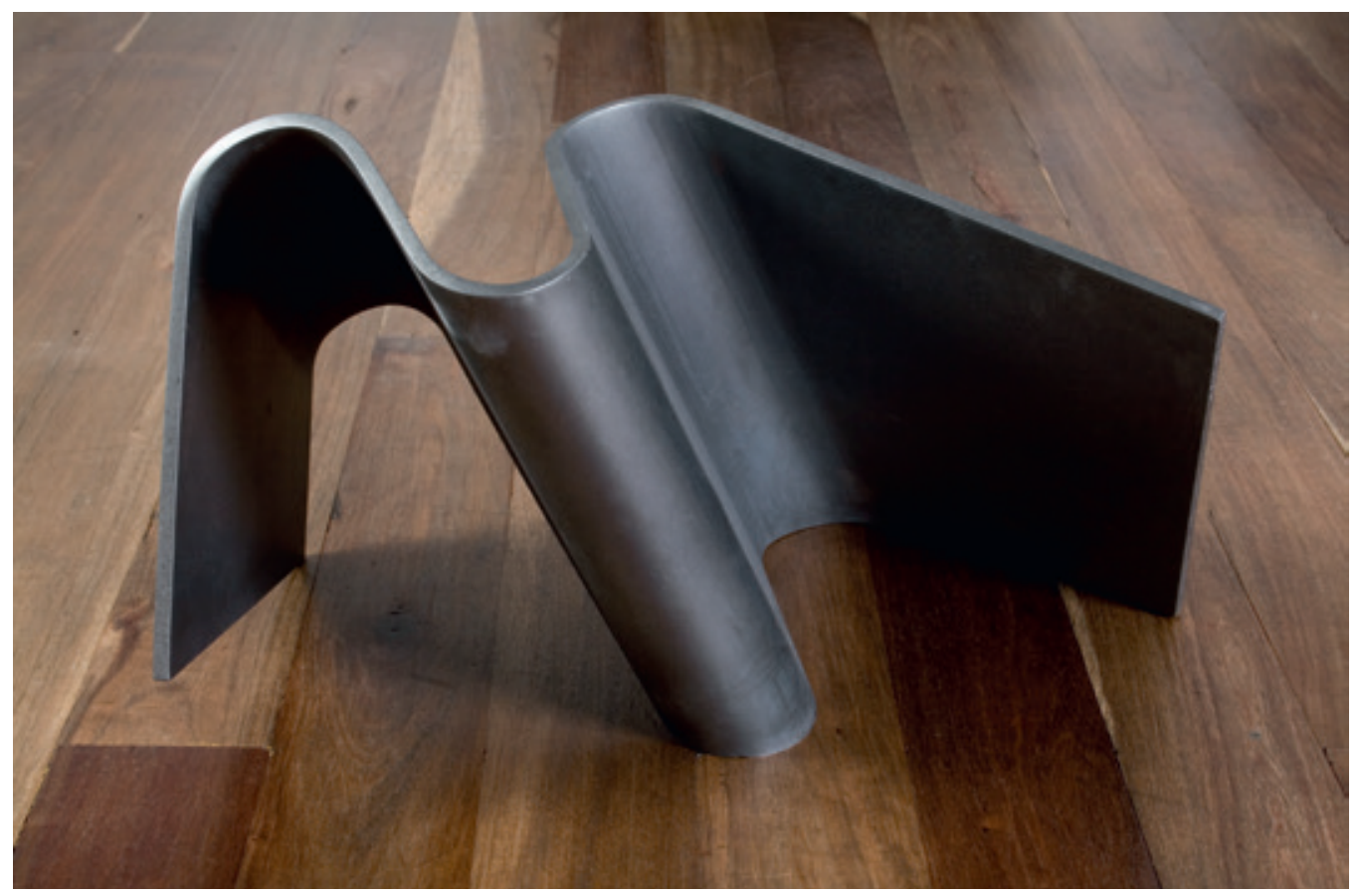

Triple diagonal, (John Castles 2008), acero, 38 × 60 × 48 cm. Fotografía: Ernesto Monsalve. 
“Estas obras -Ondulantes - superan todos los problemas de la tridimensionalidad finisecular y actual: antropomorfismo, pues la figura no aparece ni siquiera oculta; lo representacional, pues se trata de una realidad física no representada sino presentada; lo ilusorio, pues no hay "trampa al ojo"; y lo serial, que desaparece por completo".

Luis Fernando Valencia. "John Castles"

Bogotá. Alonso Garcés Galería, Agosto, 2008.

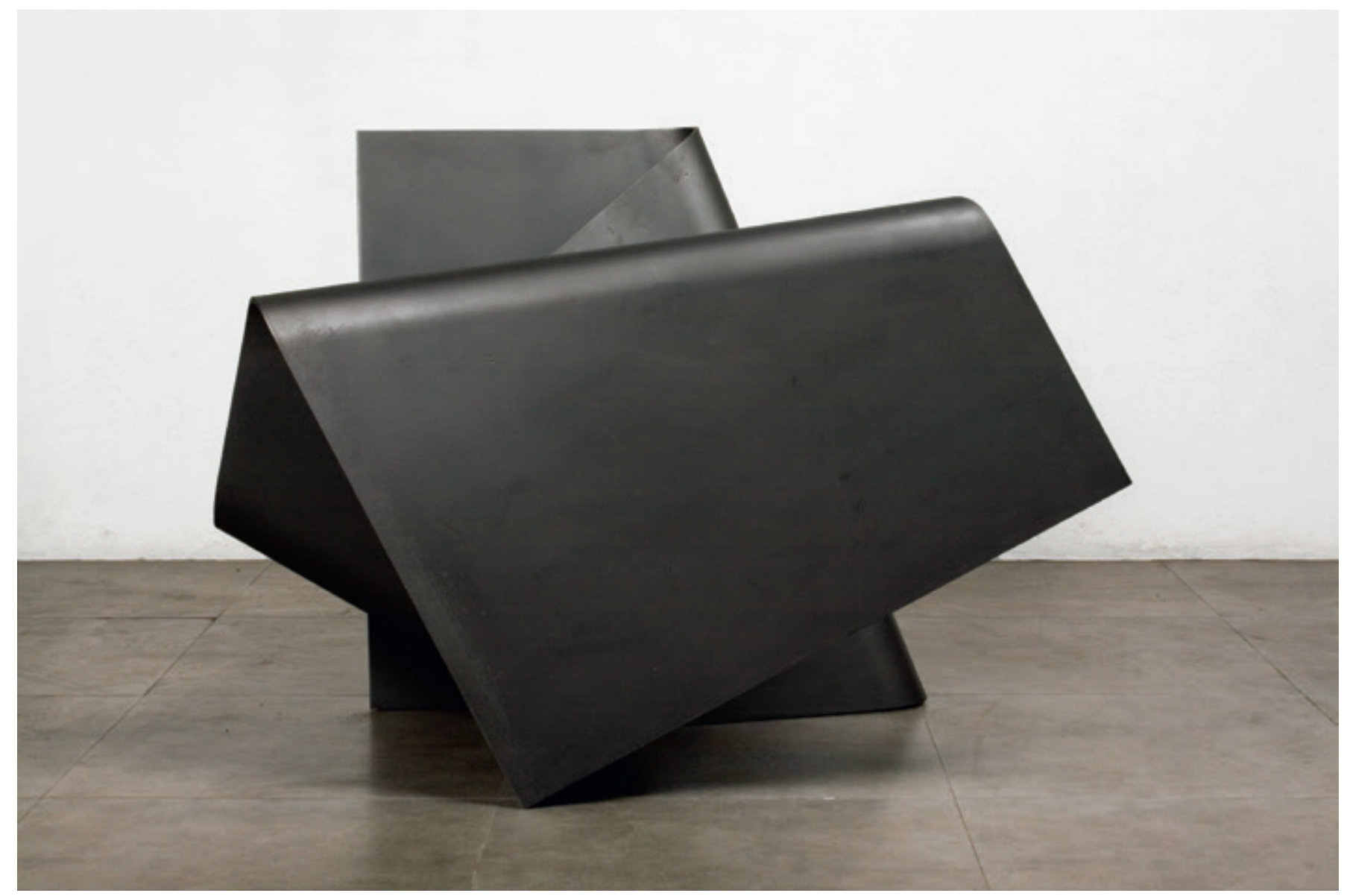

Horizontal, (John Castles 2008-09), acero, 89 x 75 x 120 cm. Fotografía: Ernesto Monsalve. 


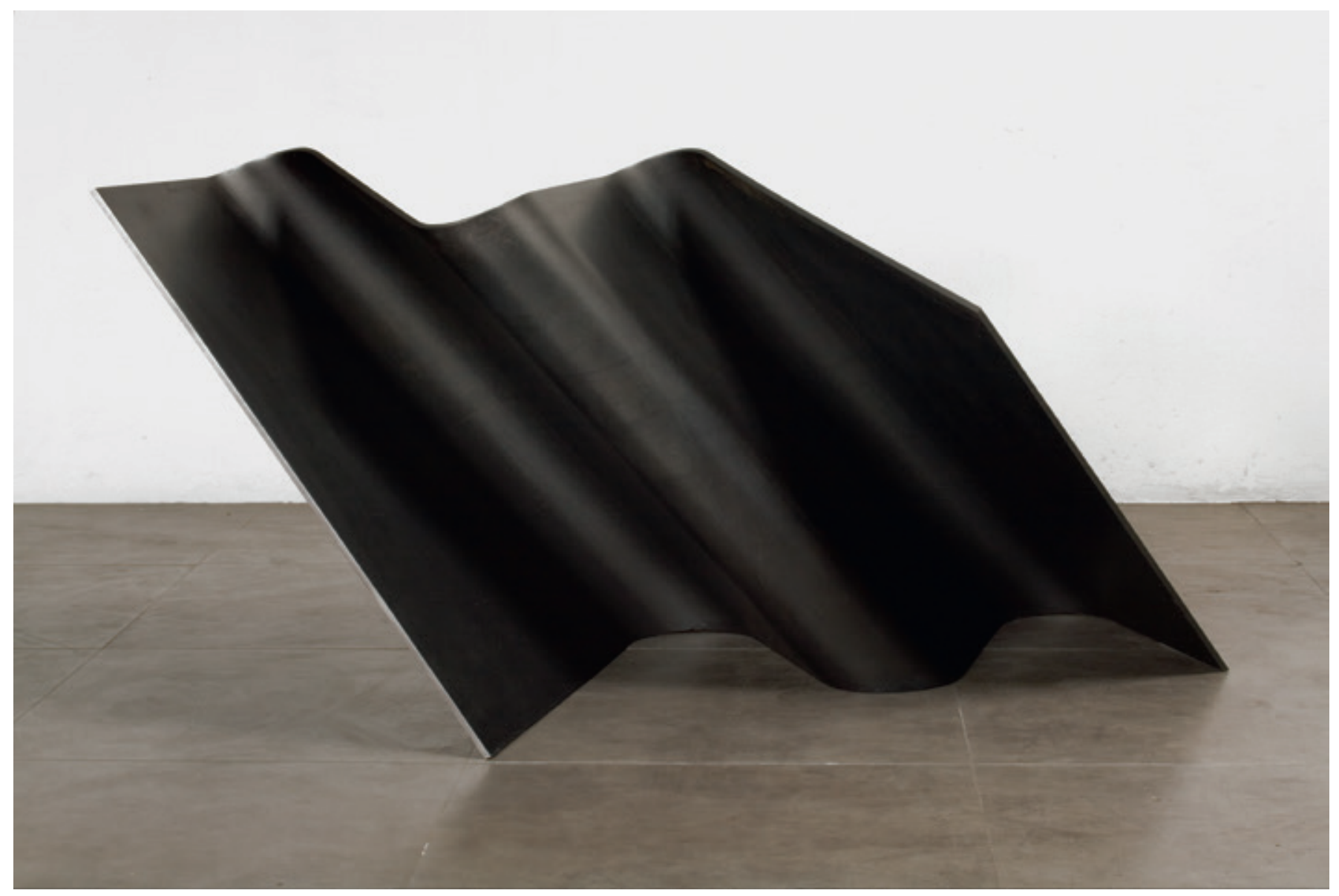

Triple 2, (John Castles 2009), acero, 70 × 86 × 92 cm. Fotografía: Ernesto Monsalve.

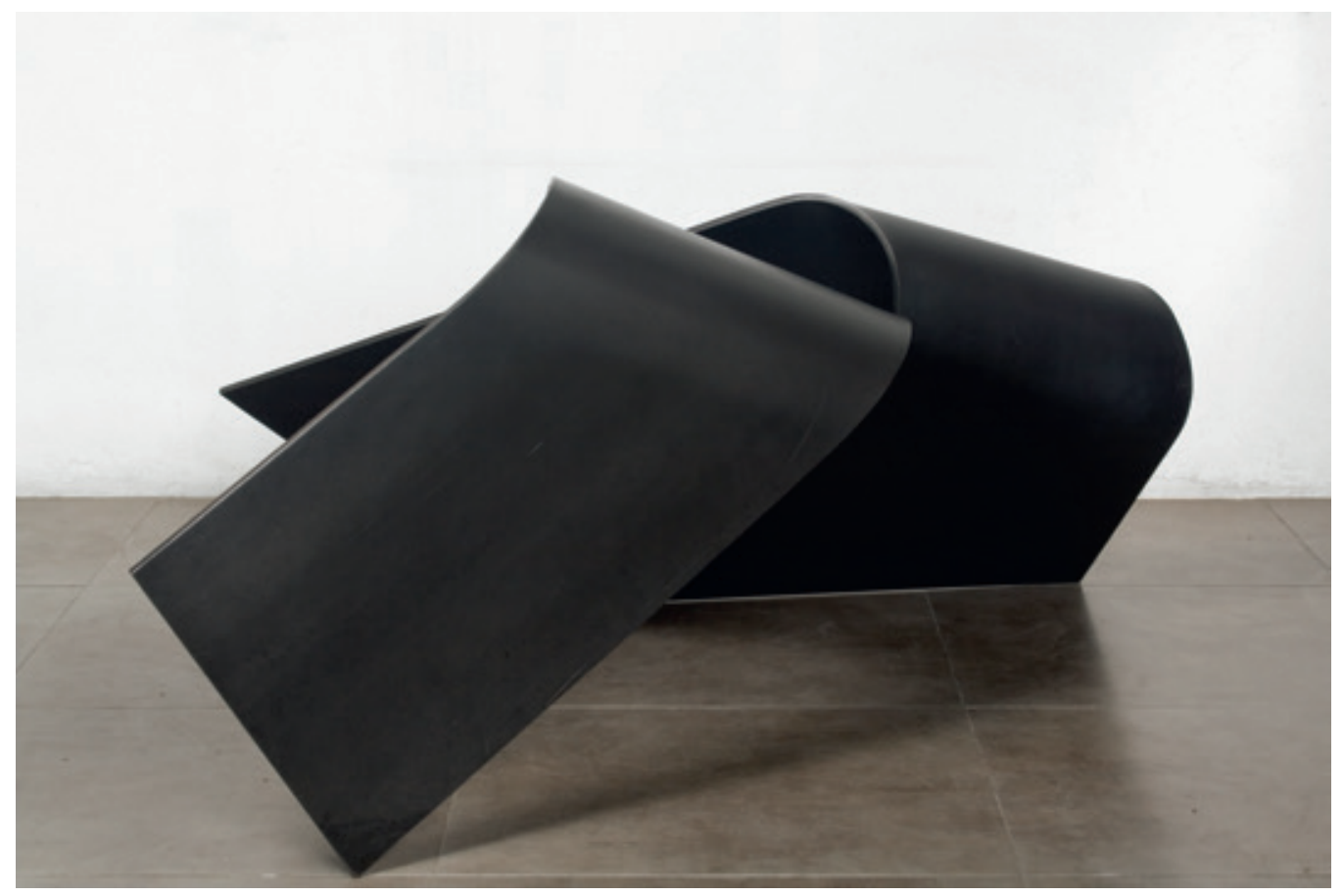

Rajada 2, (John Castles 2009), acero, 70 × 142 × 126 cm. Fotografía: Ernesto Monsalve. 


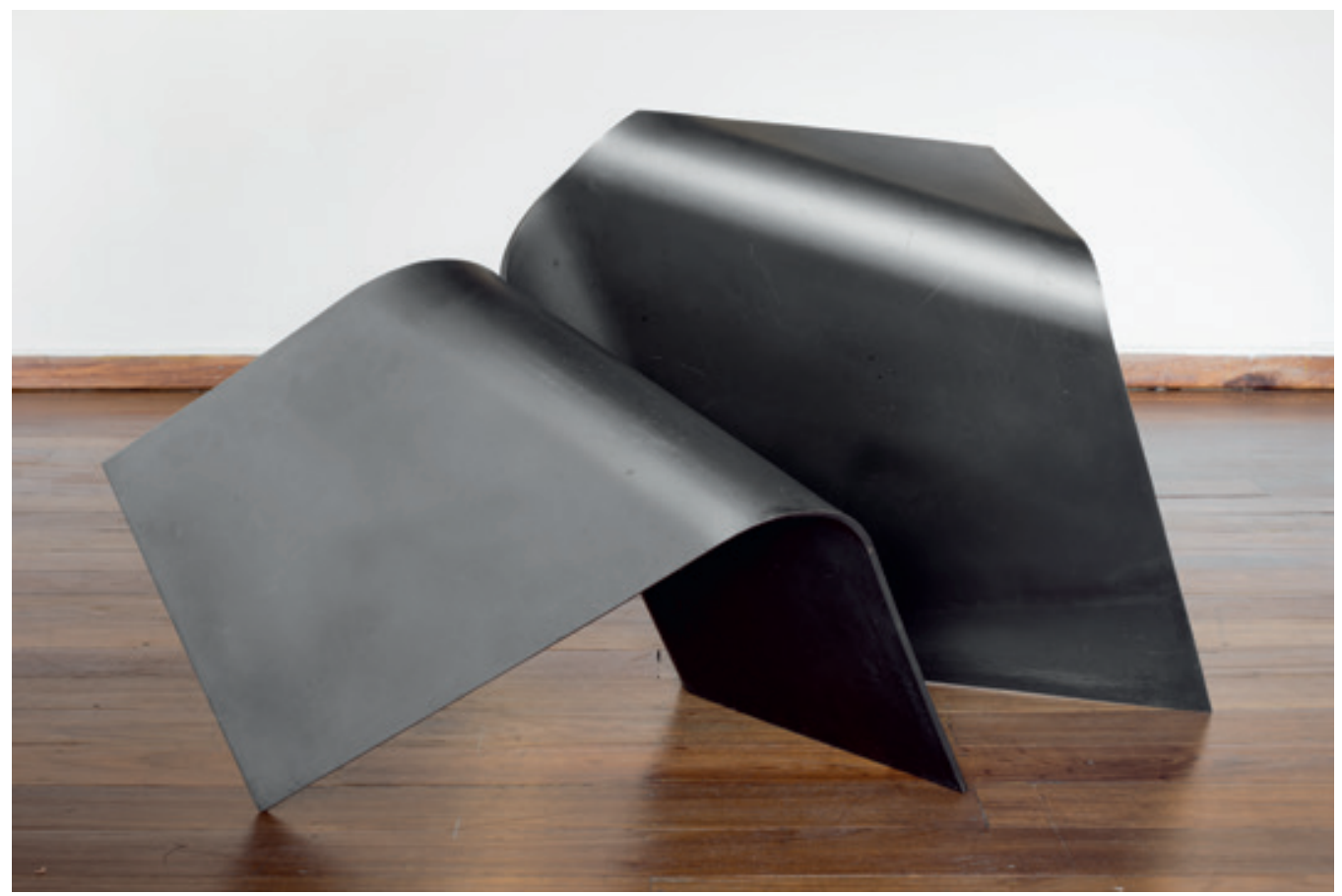

Perpendicular, (John Castles 2011), acero, 79 × 105 × 95 cm. Fotografía: Antonio Castles.

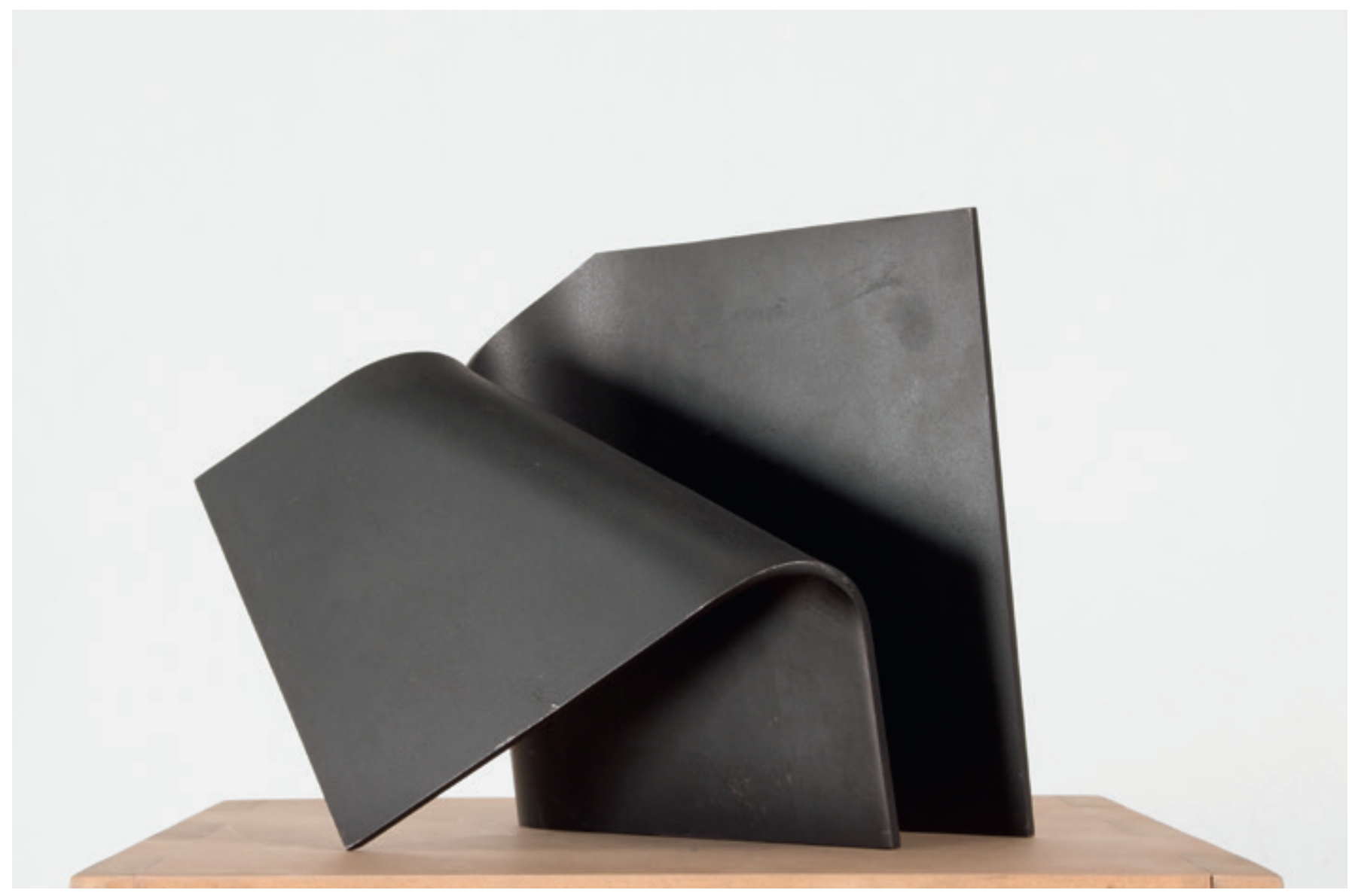

Perpendicular (John Castles 2010) acero, 16 × 23 × 32 cm. Fotografía: Antonio Castles. 
"Algunas de sus piezas serpentean, se desplazan en forma de "ese", dibujando ondas y vueltas como las serpientes. Pero unas serpientes de hierro, recias y precisas las cuales continúan armonizando las nociones de ductilidad y movimiento con las de gravedad y reciedumbre. Es esta la razón de que sus obras, por una parte, parezcan haberse doblado fácilmente, sin mayor esfuerzo, como si hubieran sido ejecutadas en algún material maleable, y por otra parte, despierten curiosidad acerca de las fuerzas y las herramientas y las máquinas utilizadas en su ejecución."

Eduardo Serrano. "Sinuosas"

Bogotá. Cámara de Comercio, Abril de 2009.

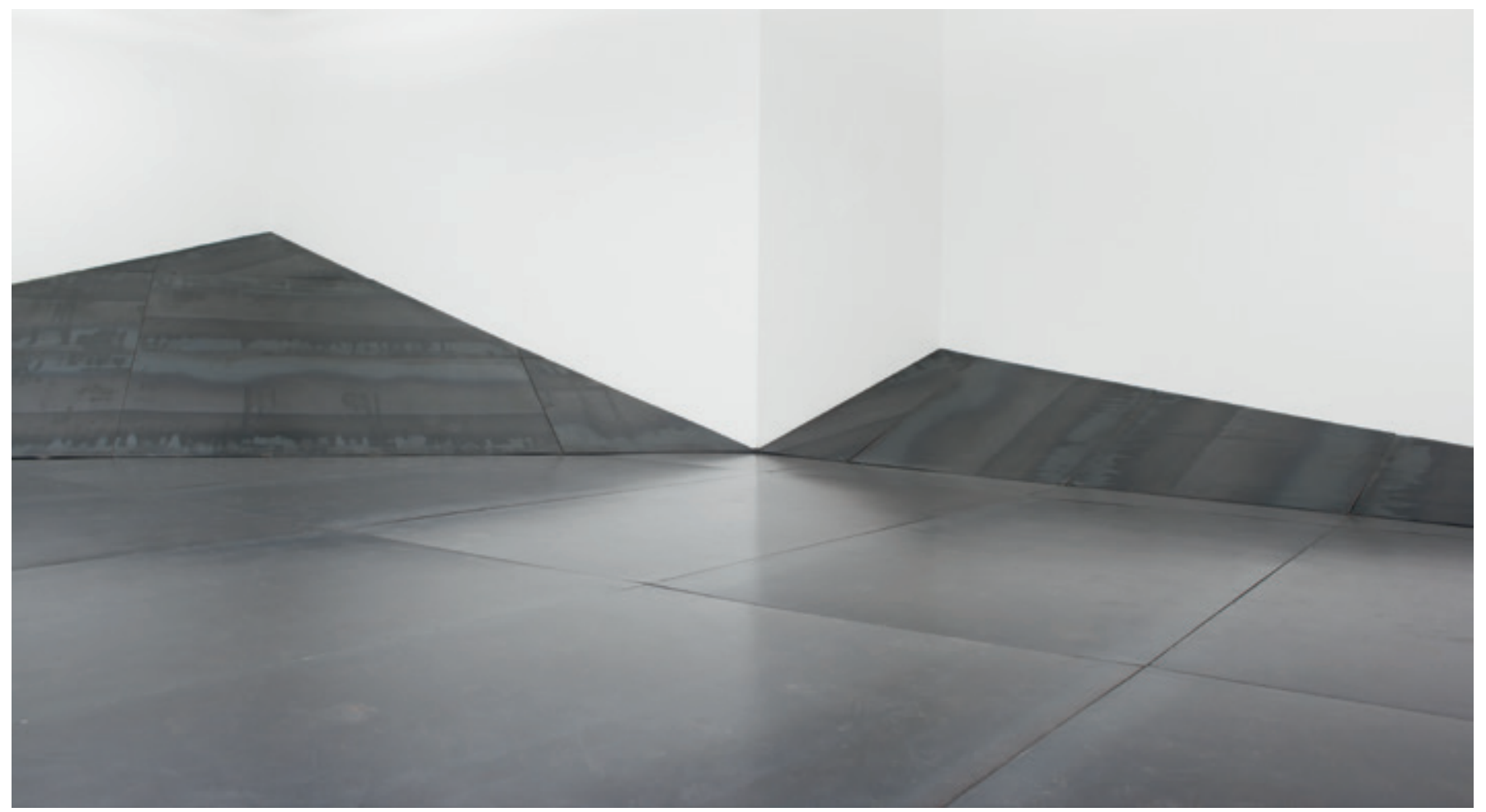

Mundo, (John Castles 2011), acero soldado, 36 m², Galería Mundo. Fotografía: Antonio Castles. 


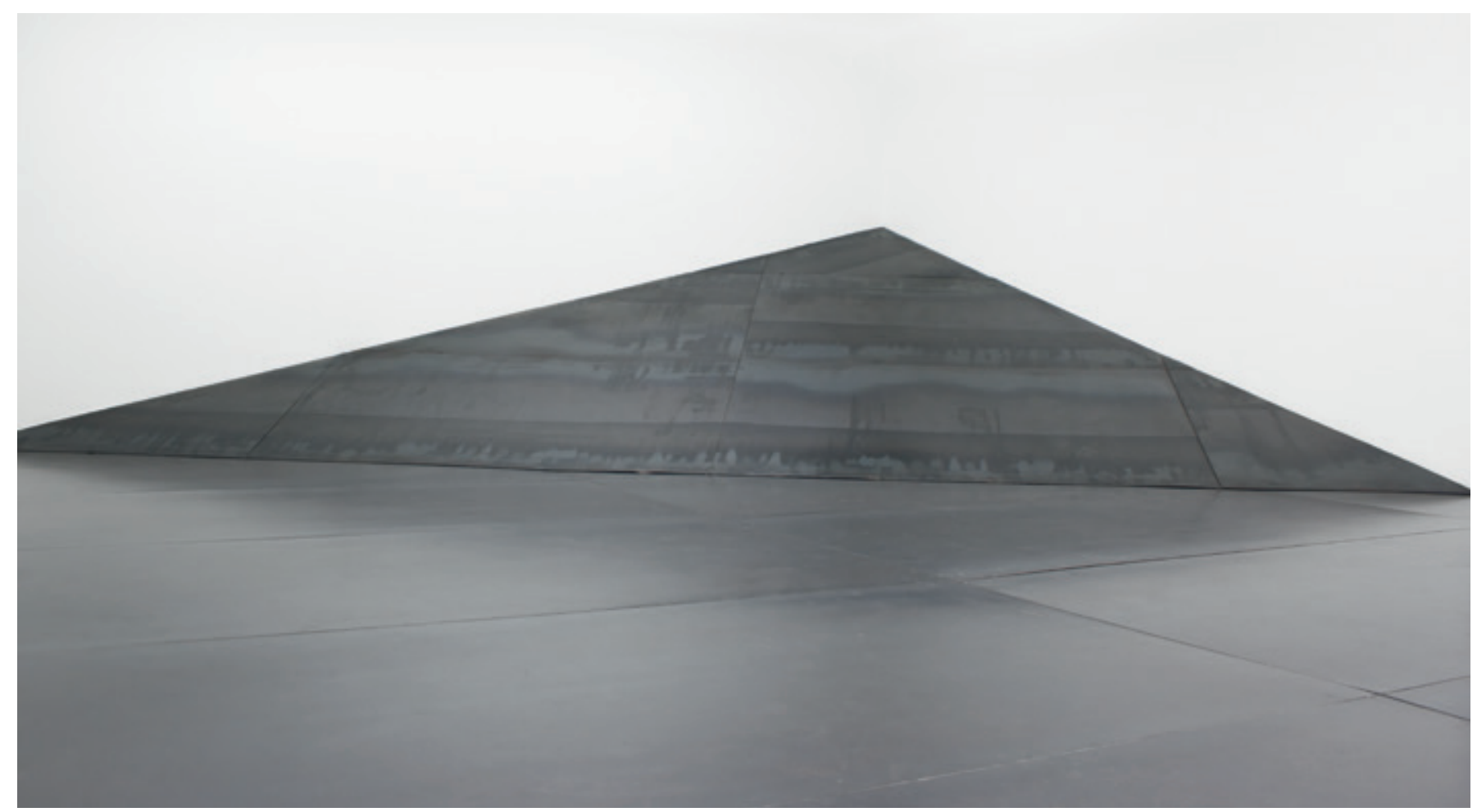

Mundo, (John Castles 2011), acero soldado, 36 m², Galería Mundo. Fotografía: Antonio Castles.

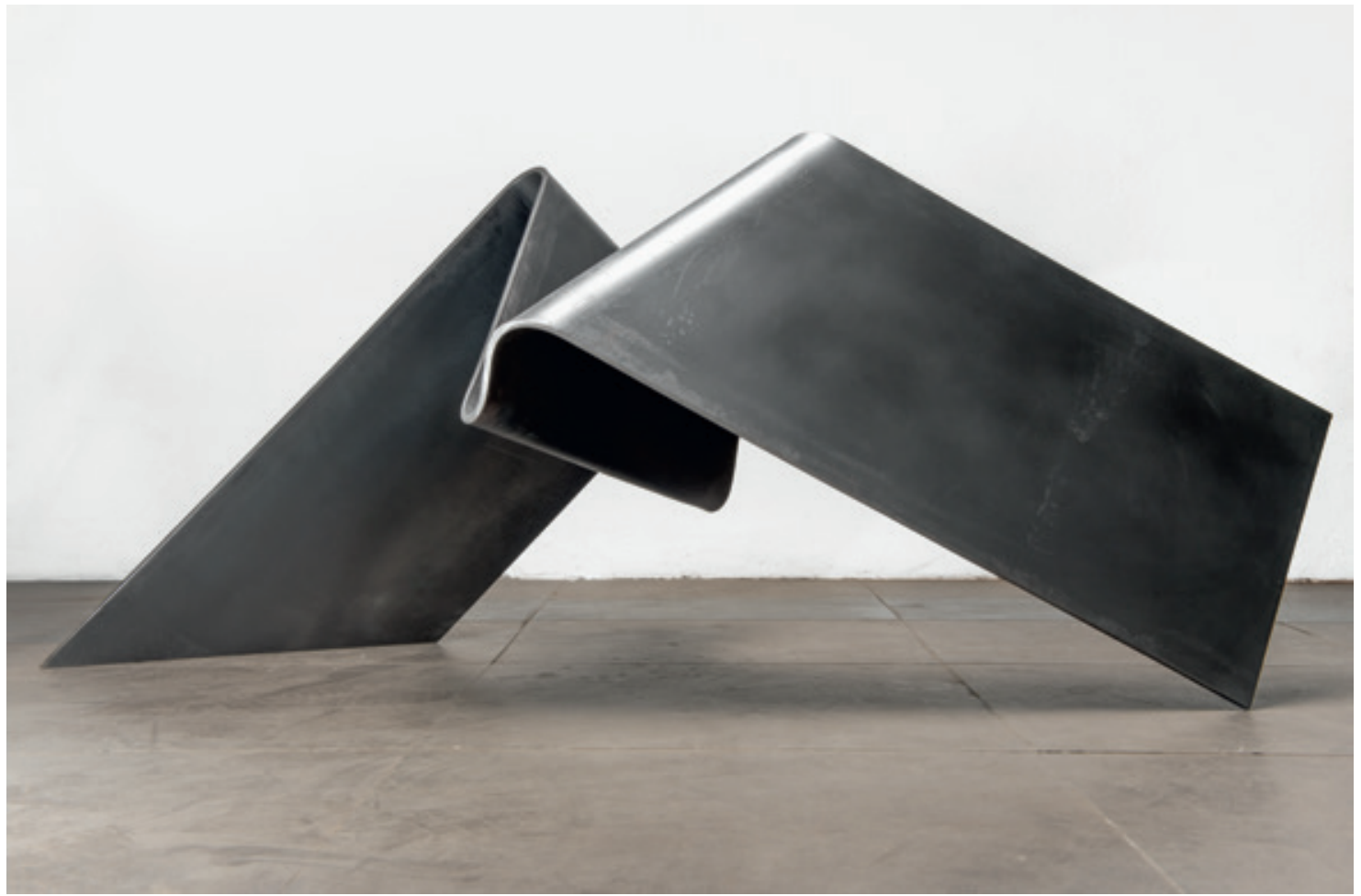

Paralelo, (John Castles 2014), acero, 67 × 98 × 135 cm. Fotografía: Antonio Castles. 


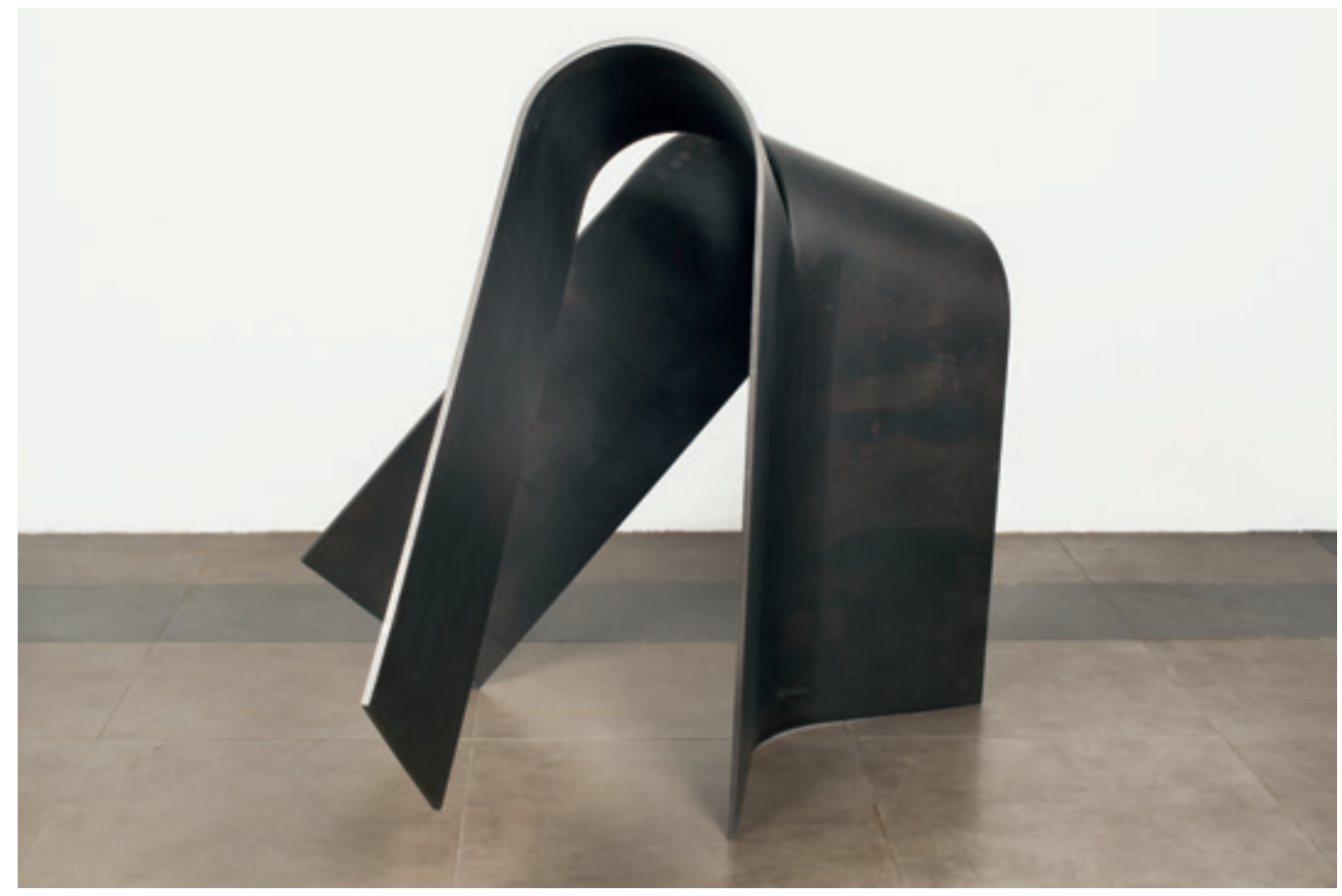

Abierto posterior, (John Castles 2014), acero cm. Fotografía: Antonio Castles.

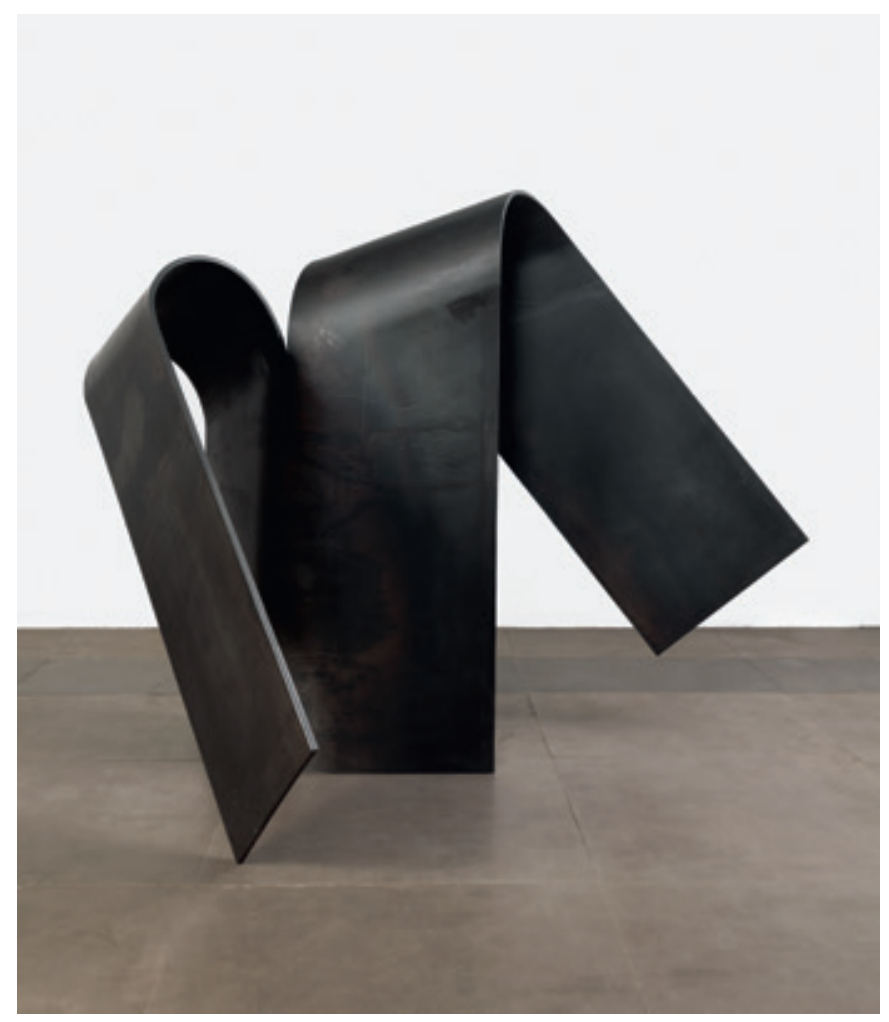

Diagonal alterno, (John Castles 2014), acero, $110 \times 77 \times 120 \mathrm{~cm}$. Fotografía: Ernesto Monsalve. 


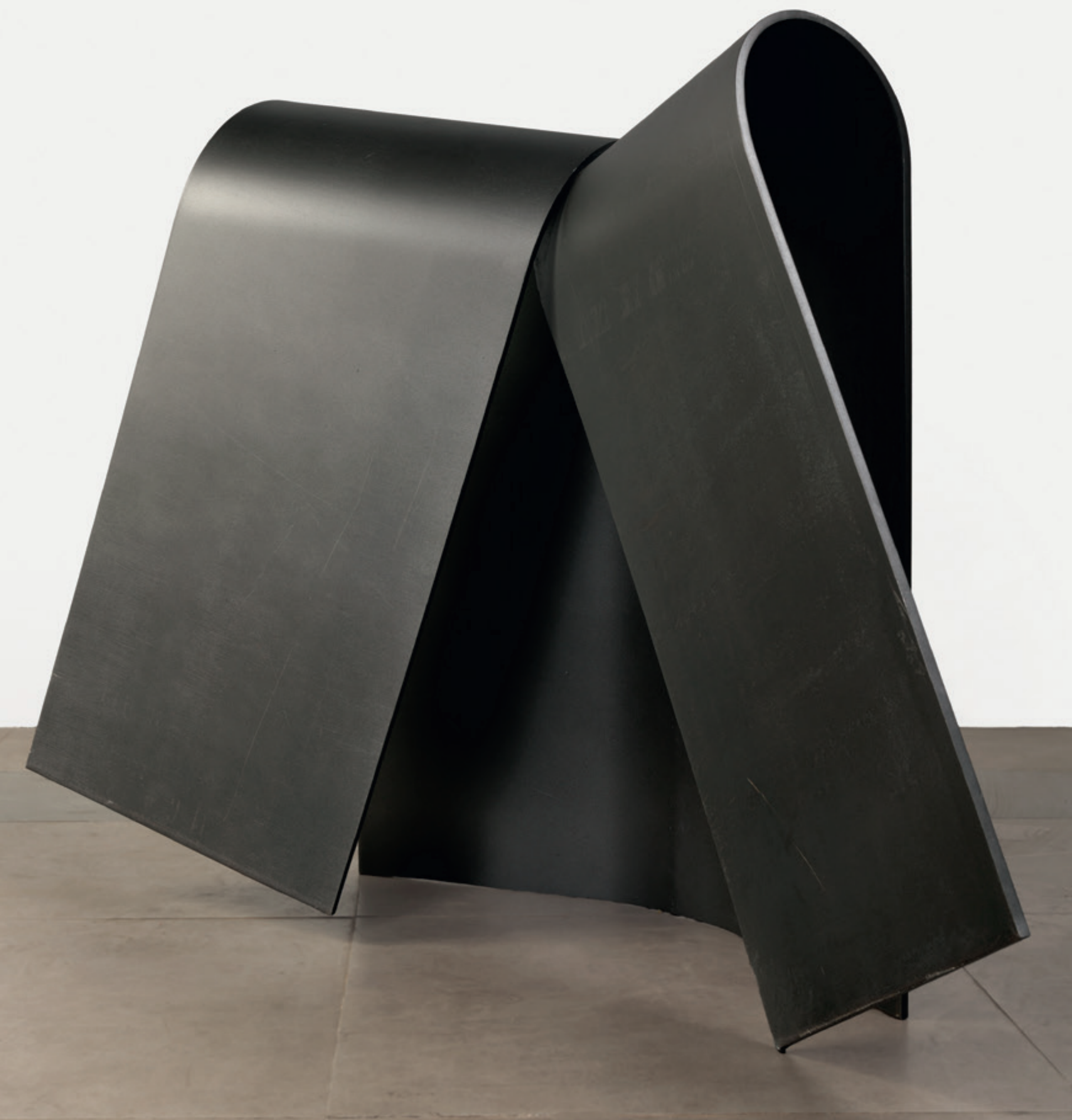


"Las esculturas a partir de una lamina pueden sostenerse por si solas, al tiempo que exhiben sus formas austeras y elegantes. La desenvoltura con que son resueltas y solucionan su condición las hacen parecer irónicamente livianas, y el metal aparenta ser un frágil papel que se desdobla. Castles desafía así no solo las propiedades físicas del material sino que es capaz de construir una poética para sus formas."

Miguel González. "John Castles"

Bogotá. ArtNexus No.142, pg. 44-49, Marzo - Mayo 2015.

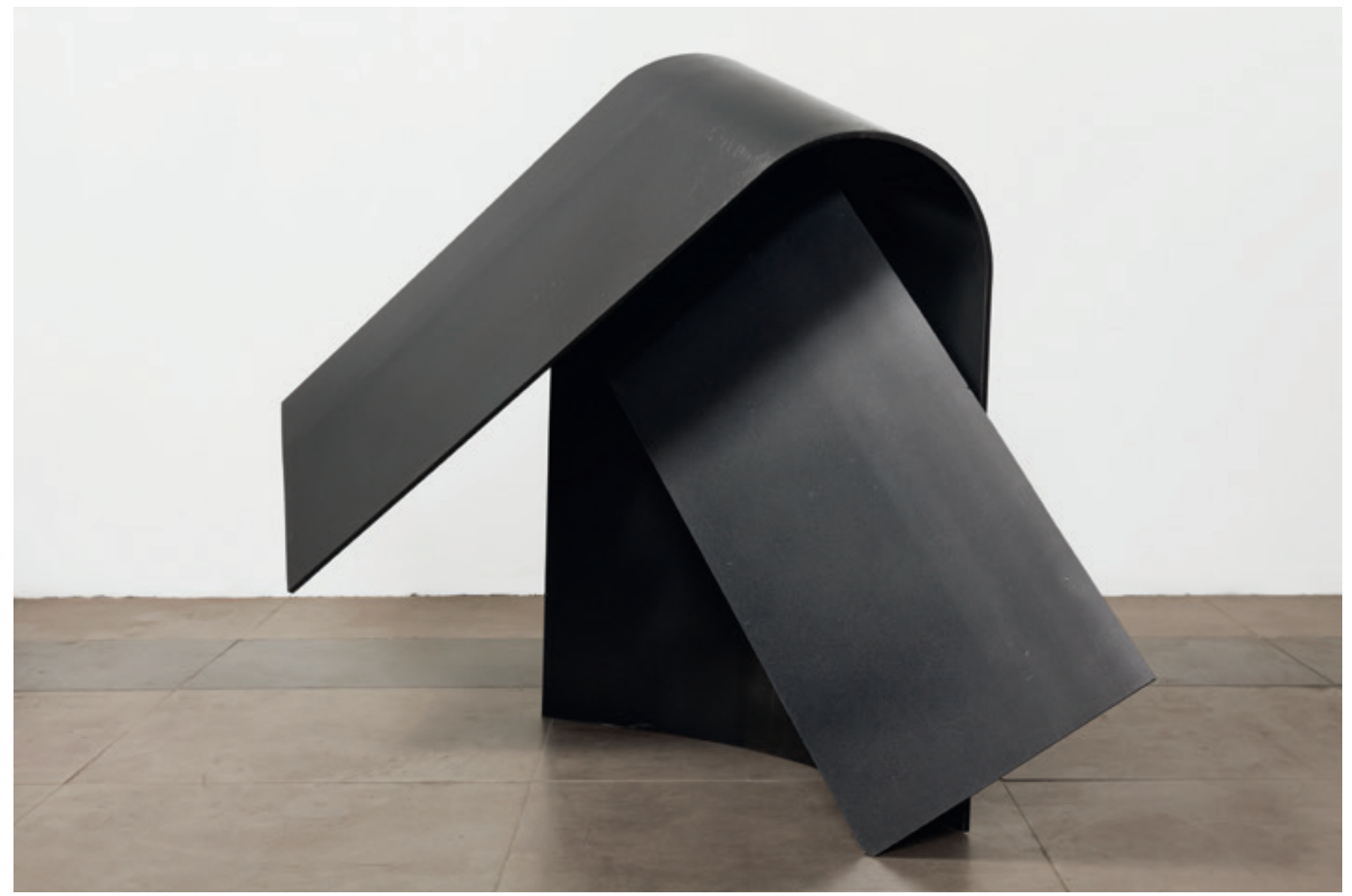

Cruzado frontal, (John Castles 2016), acero, 93 × 40 × 130 cm. Fotografía: Ernesto Monsalve. 

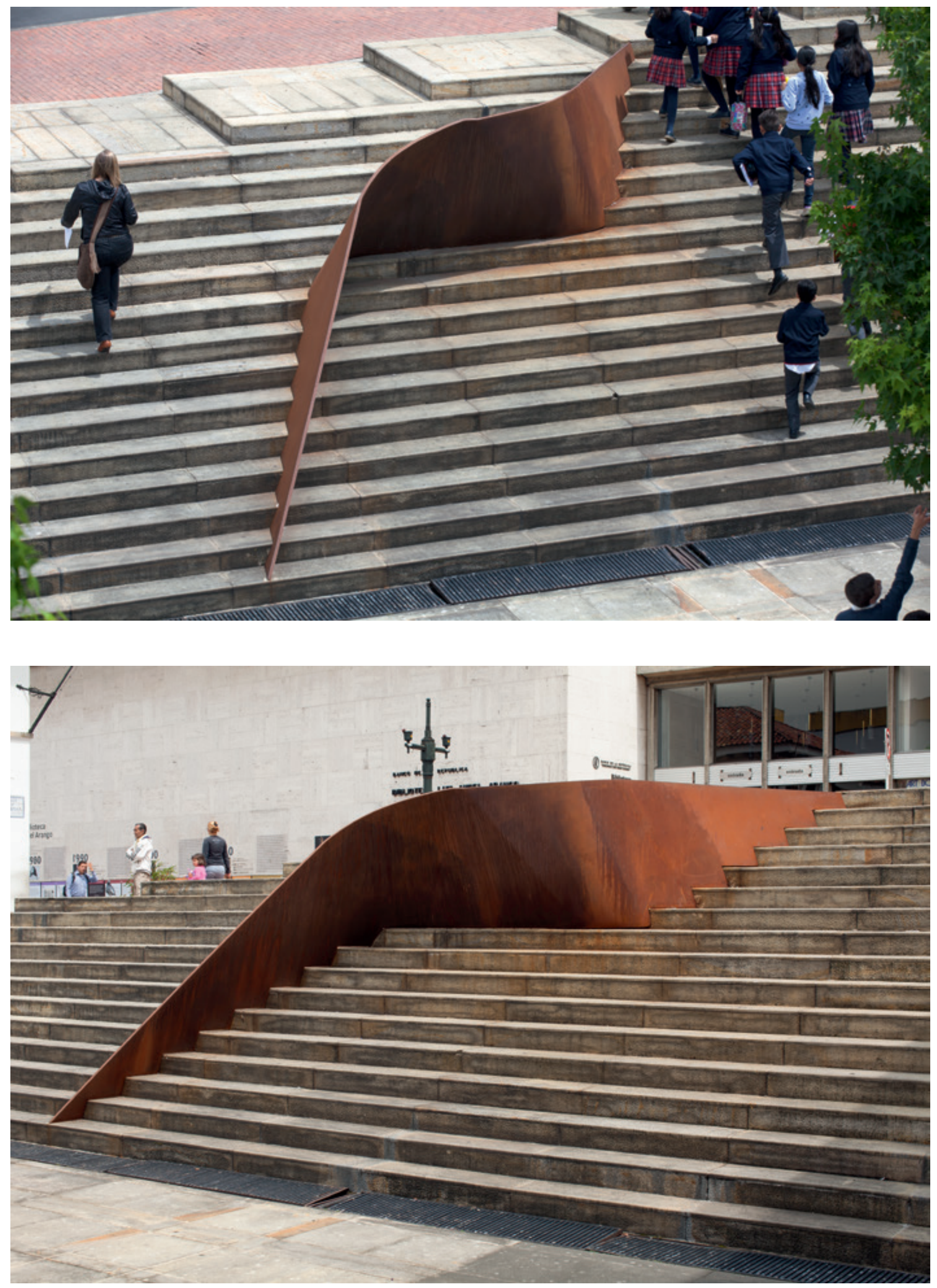

Escalonado, (John Castles 2016), acero, 297 × 515 × 472 cm, Museo de Arte Miguel Urrutia, MAMU. Fotografía: Ernesto Monsalve. 


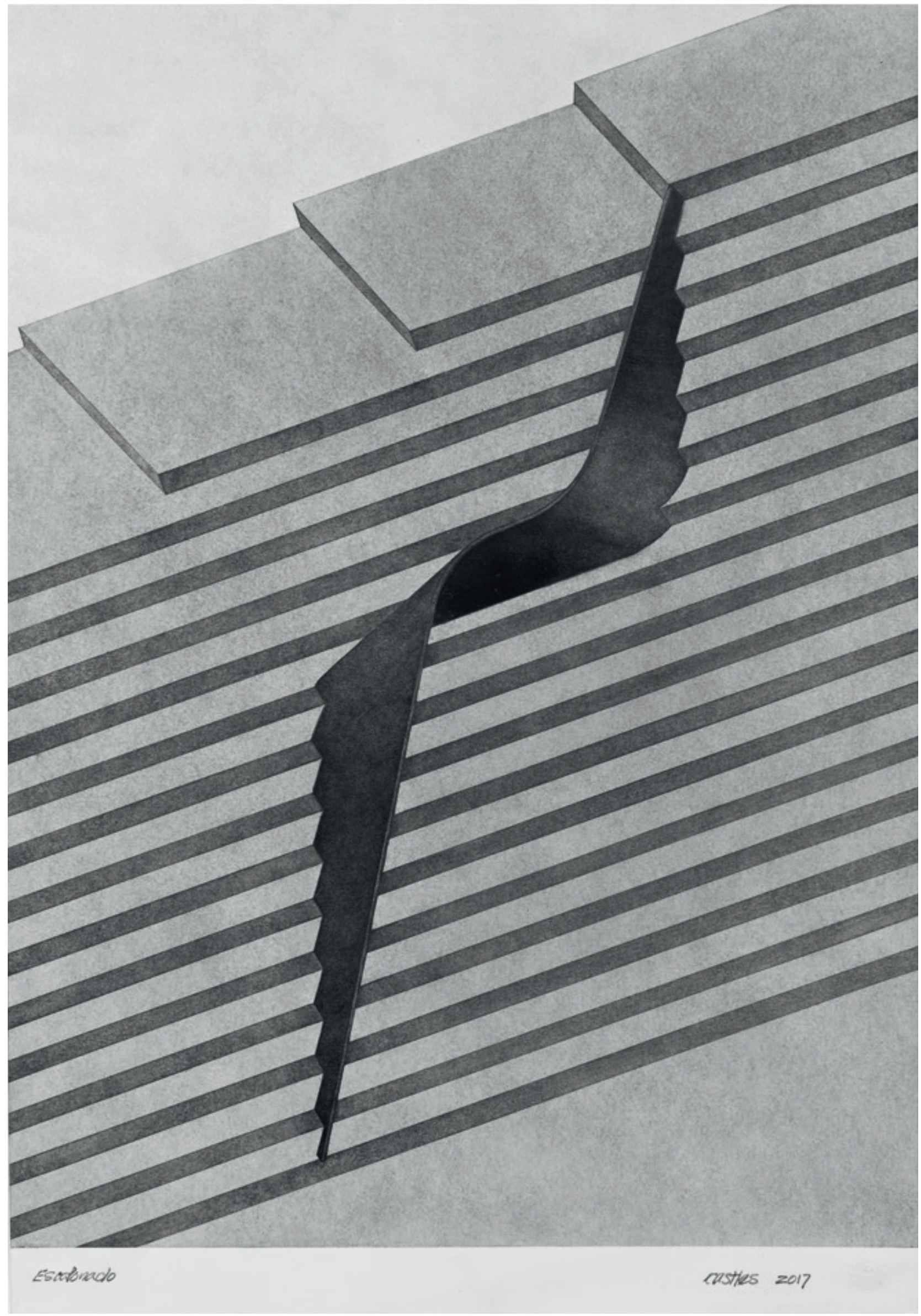

Escalonado, (John Castles 2017), grafito sobre papel, 65,5 × 45,5 cm. Fotografía: Ernesto Monsalve. 


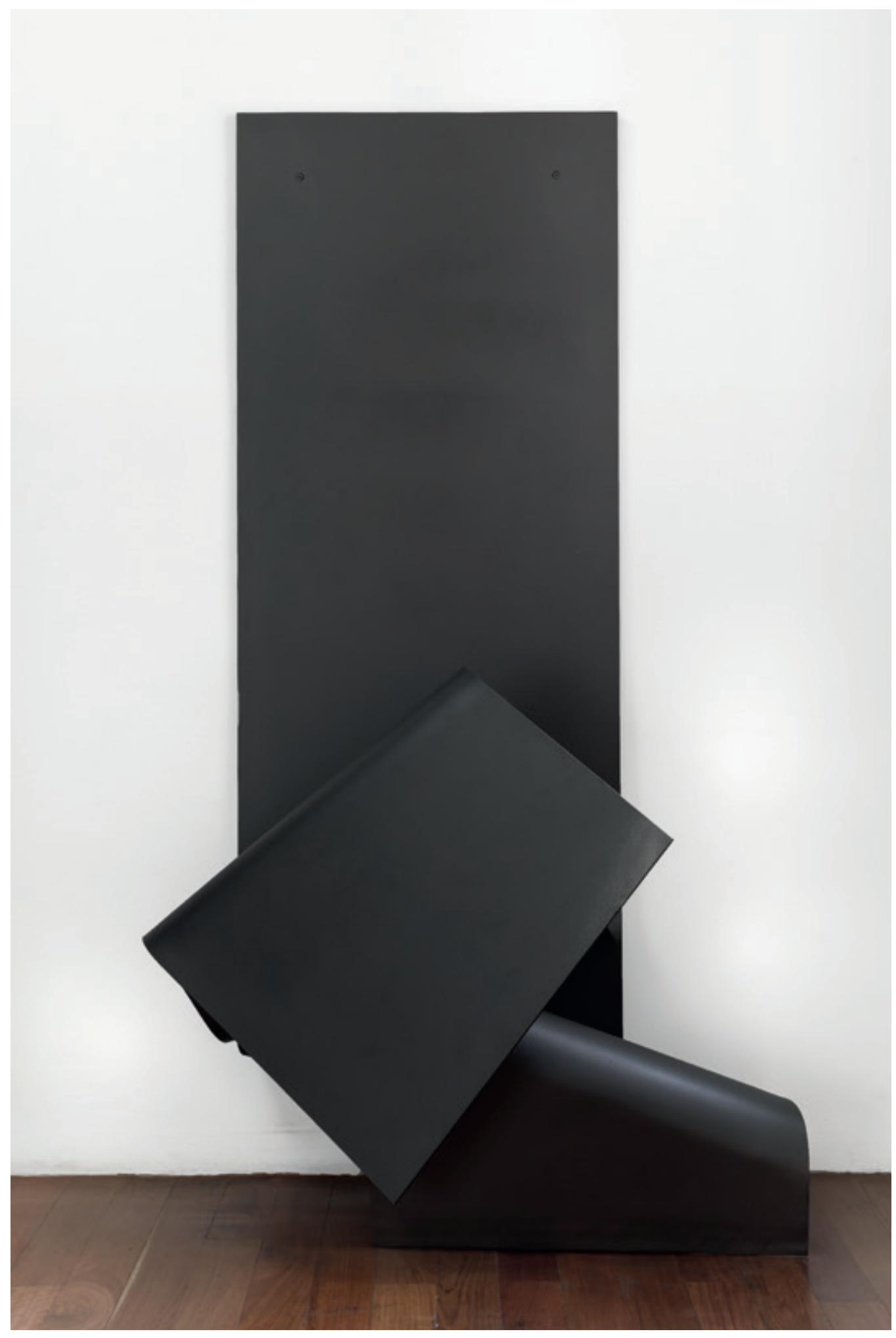

Cruzada, (John Castles 2017), acero soldado, 165,5 x 58 x 90 cm. Fotografía: Ernesto Monsalve. 


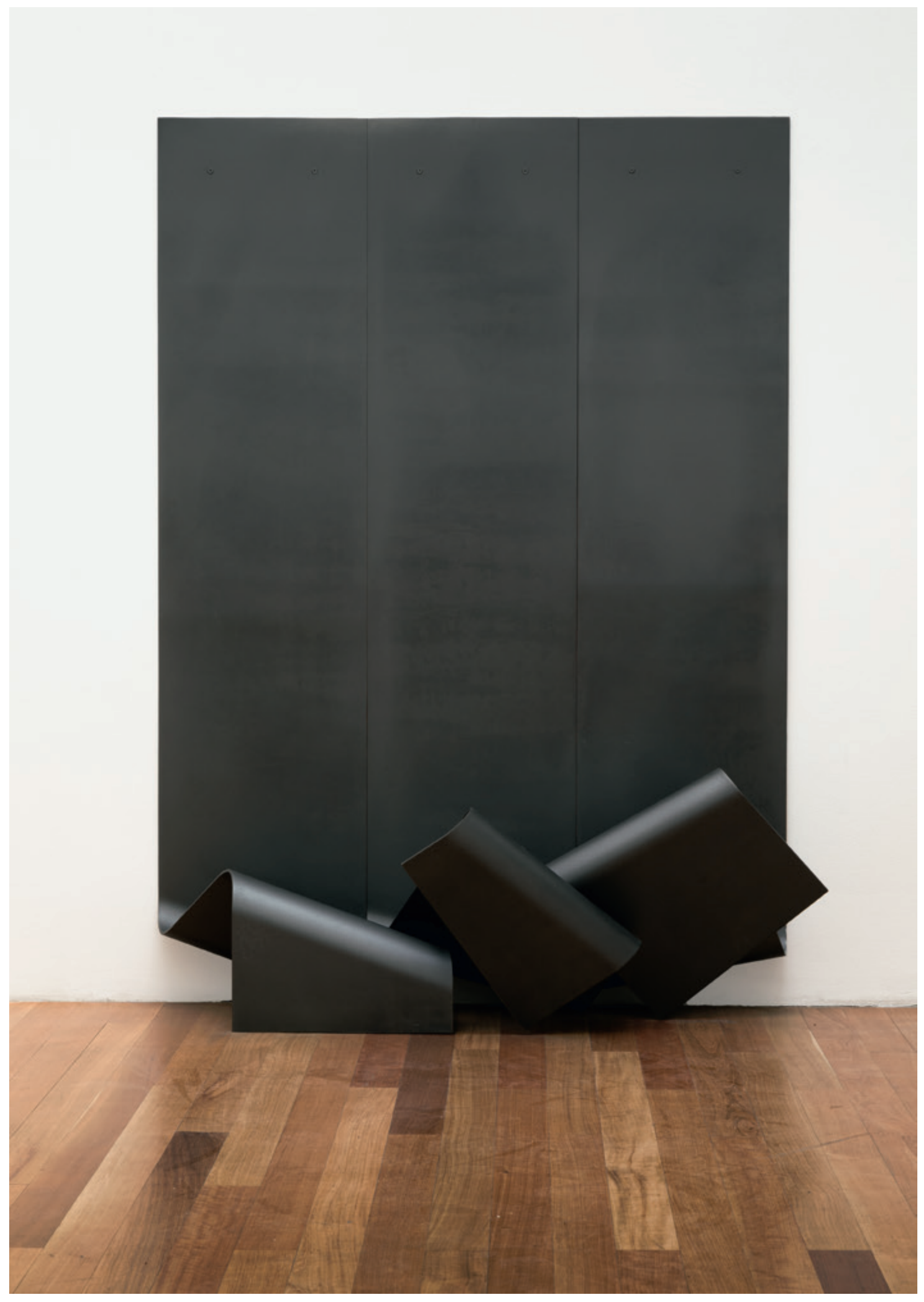




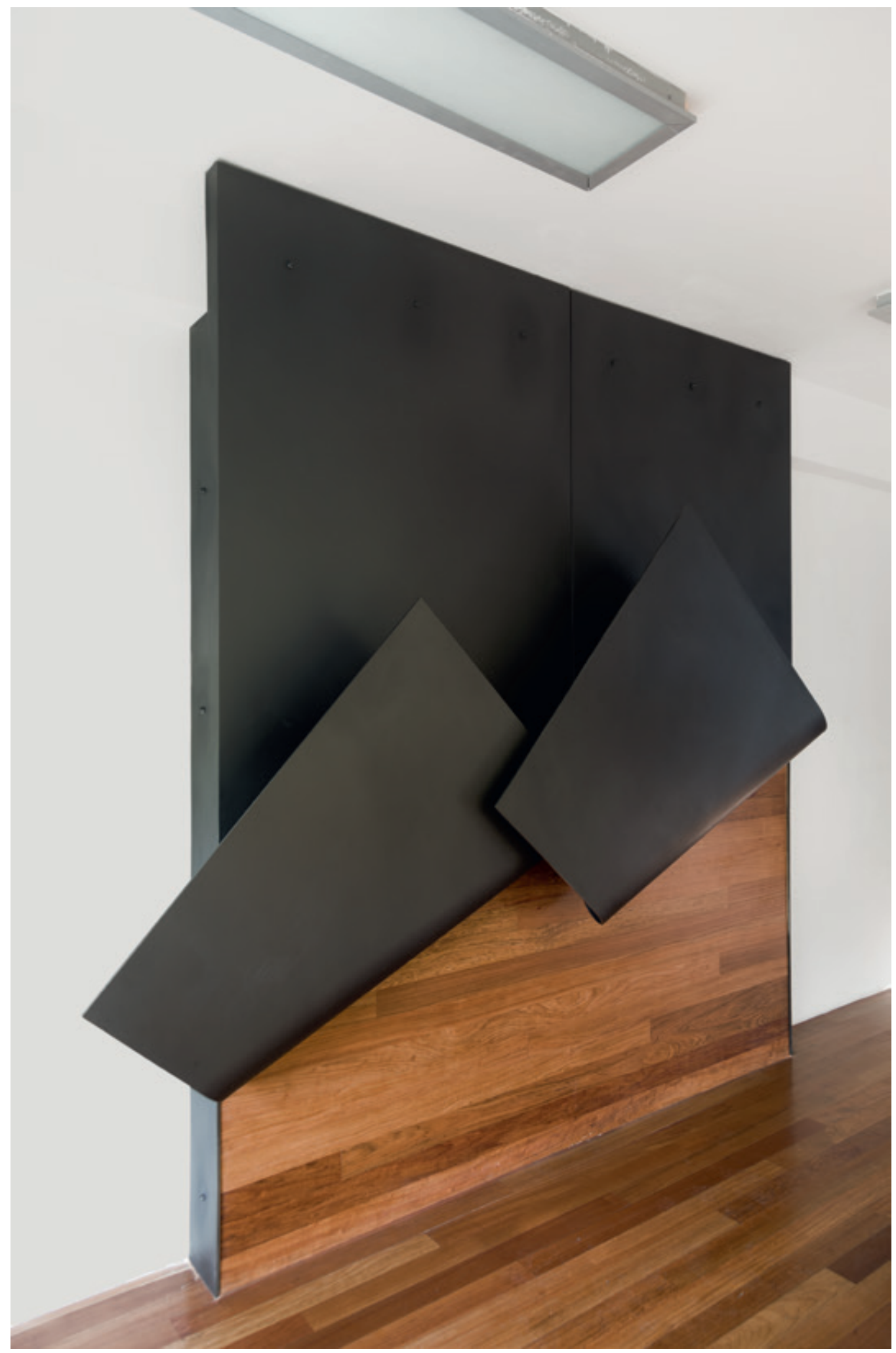

Ascendente, (John Castles 2017), acero y madera, 279 × 278 x 47 cm. Fotografía: Ernesto Monsalve. 


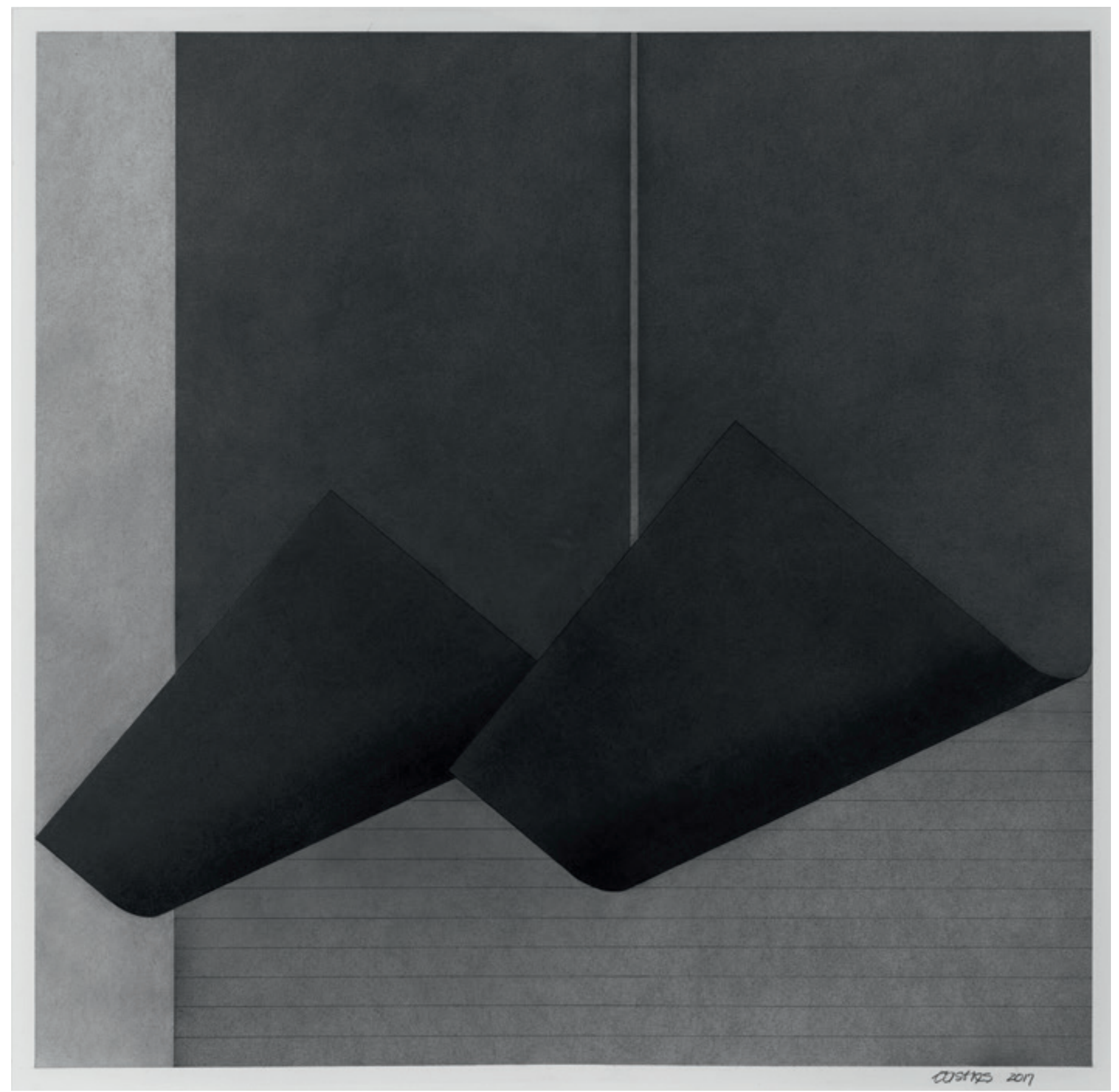

Ascendente, (John Castles 2017), grafito sobre papel, 70 x 70 cm. Fotografía: Ernesto Monsalve. 
“Tanto en su obra pública, donde sus convicciones encuentran un punto de convergencia con las características espaciales del lugar, como en sus obras más organizas o incluso en aquellas otras donde se permite explorar una sensualidad sometida de las formas, siempre esta más o menos latente, una arquitectura donde no hay solución que no esté pensada. En la obra de Castles el azar no existe, no concurre porque es contrario a la propia naturaleza de su trabajo y en la inexistencia de ese azar, esta la perdurabilidad y la independencia misma de su obra."

Osbel Suárez. "John Castles y la escultura colombiana del último medio siglo" Bogotá. Galería Nueveochenta. "John Castles entre el suelo y la pared”, Septiembre 2015. 